\title{
Asymmetrically Shaped Pseudomorphic Modulation Doped Structure for Microwave Detection
}

\author{
A. KoziČ $\check{C}^{a, *}, \check{C}$. PašKeviČ ${ }^{a}$, A. SuŽIedélis ${ }^{a}$, J. Gradauskas $^{a}$, \\ S. AŠMONTAS ${ }^{a}$, A. Szerling ${ }^{b}$ AND H. WrzesińsKA ${ }^{b}$ \\ ${ }^{a}$ Semiconductor Physics Institute, A. Goštauto 11, 01108 Vilnius, Lithuania \\ ${ }^{b}$ Institute of Electron Technology, al. Lotnikow 32/46, 02- 668 Warsaw, Poland
}

(Received October 2, 2006)

In this paper we propose a microwave detector based on a AlGaAs/ InGaAs/GaAs structure. Its operation relies on non-uniform carrier heating of the two-dimensional electron gas in the microwave electric fields which is a result of the asymmetric shape of the device fabricated on the base of pseudomorphic modulation doped AlGaAs/InGaAs/GaAs structure. The voltage sensitivity of the device at nitrogen temperature is $38 \mathrm{~V} / \mathrm{W}$ for $10 \mathrm{GHz}$ radiations and is higher compared to that of modulation doped AlGaAs/GaAs of the same configuration.

PACS numbers: 85.30.De, 72.30.+q

\section{Introduction}

Detection of $\mathrm{GHz}$ - THz electromagnetic radiation is possible utilizing a free carrier heating phenomenon [1]. In this paper we extend the family of hot carrier based microwave sensors. Such detectors reveal a broad band of operation from $10 \mathrm{GHz}$ up to $30 \mathrm{THz}[2]$.

However, the drawback of these detectors is their small sensitivity. One solution of this problem is to use a semiconductor material with higher carrier mobility, e.g. to use modulation doped structures with two-dimensional electron gas (2DEG) [3]. To obtain higher mobility of the 2DEG, a thin layer of narrow-gap semiconductor may be introduced. Pseudomorphic modulation doped AlGaAs/InGaAs/GaAs heterostructures benefit from higher electron mobility and saturation velocity in the InGaAs quantum well channel accompanied by better

*corresponding author; e-mail: antoni@pfi.lt 
confinement properties and higher two-dimensional electron gas density when compared to conventional AlGaAs/GaAs heterostructures [4]. For example, modern field transistors, pseudomorphic high electron mobility transistors (HEMTs), use a layer of a material with a narrow band-gap of energy and high electron mobility. From the reason of the difference of a crystal lattice, constant InGaAs with a small percent of indium is used. The layer should be thin enough not exceeding the critical thickness. When the InGaAs layer thickness exceeds the critical one then the electrical and optical features of the modulation doped structure undergo considerable changes due to the strains of crystal lattice [5].

In this work we present a microwave device containing an InGaAs quantum well 2DEG channel. Qualitative interpretation of experimental results of detection properties of asymmetrically shaped pseudomorphic modulation doped $\mathrm{AlGaAs} / \mathrm{InGaAs} / \mathrm{GaAs}$ heterostructures in microwave electric field is presented in this paper.

\section{Samples}

The $\mathrm{Al}_{0.28} \mathrm{Ga}_{0.72} \mathrm{As} / \mathrm{In}_{0.15} \mathrm{Ga}_{0.85} \mathrm{As} / \mathrm{GaAs}$ pseudomorphic structures have been grown by molecular beam epitaxy (MBE) technique on semi-insulating GaAs substrate with a superlattice buffer. The buffer superlattice was composed of 10 periods of undoped GaAs $/ \mathrm{Al}_{0.28} \mathrm{Ga}_{0.72}$ As layers. Figure 1 depicts the schematic view of the structure as well as its energetic band diagram. The undoped $i$-GaAs cap layer of $20 \mathrm{~nm}$ thickness was designed to prevent the doped AlGaAs layer against oxidation. The thickness of the doped $n^{+}-\mathrm{Al}_{0.28} \mathrm{Ga}_{0.72}$ As layer was $80 \mathrm{~nm}$ and the Si doping density reached the value of $N_{\mathrm{d}} \sim 10^{18} \mathrm{~cm}^{-3}$. The undoped $i$ - $\mathrm{Al}_{0.28} \mathrm{Ga}_{0.72} \mathrm{As}$ layer of $45 \mathrm{~nm}$ thickness separated the $n^{+}-\mathrm{Al}_{0.28} \mathrm{Ga}_{0.72}$ As layer from $i$-InGaAs quantum well region where the 2DEG channel was formed. The thickness of the $\operatorname{In}_{0.15} \mathrm{Ga}_{0.85}$ As channel was $10 \mathrm{~nm}$. Electron mobility in the two-

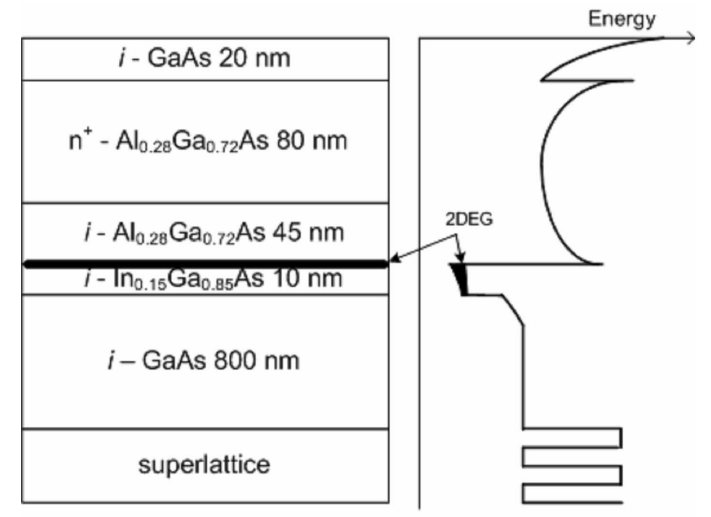

(a)

(b)

Fig. 1. Design of the MBE grown pseudomorphic modulation doped AlGaAs/ InGaAs/GaAs structures (a) and energetic band diagram of it (b). 
-dimensional electron gas channel was $\mu=6.1 \times 10^{3} \mathrm{~cm}^{2} \mathrm{~V}^{-1} \mathrm{~s}^{-1}$ at room temperature and $\mu=2.74 \times 10^{5} \mathrm{~cm}^{2} \mathrm{~V}^{-1} \mathrm{~s}^{-1}$ at liquid nitrogen temperature.

The asymmetrical mesa shape of the structure was formed using wet etching technique. The etching was carried out slightly deeper than the doped $n^{+}-\mathrm{Al}_{0.28} \mathrm{Ga}_{0.72} \mathrm{As}$ layer. The lateral dimension of the narrowest part of the asymmetrically shaped structure was in $5 \div 7 \mu \mathrm{m}$ range. Second photolithography process was done for the formation of the patterns of metallic contacts that were fabricated by thermal evaporation of $\mathrm{Ni} / \mathrm{Au} / \mathrm{Ge} / \mathrm{Ni} / \mathrm{Au}=$ $10 \mathrm{~nm} / 300 \mathrm{~nm} / 70 \mathrm{~nm} / 200 \mathrm{~nm}$ through a photoresist mask in $3 \times 10^{-6}$ Torr vacuum. The pattern of metal contacts was formed by a lift-off technique. A rapid annealing of the evaporated metal contacts was performed at $430^{\circ} \mathrm{C}$ for 40 seconds in forming gas $\mathrm{H}_{2}$ atmosphere. Figure 2 shows the SEM picture of the asymmetrically shaped $\mathrm{AlGaAs} / \mathrm{InGaAs} / \mathrm{GaAs}$ sample.

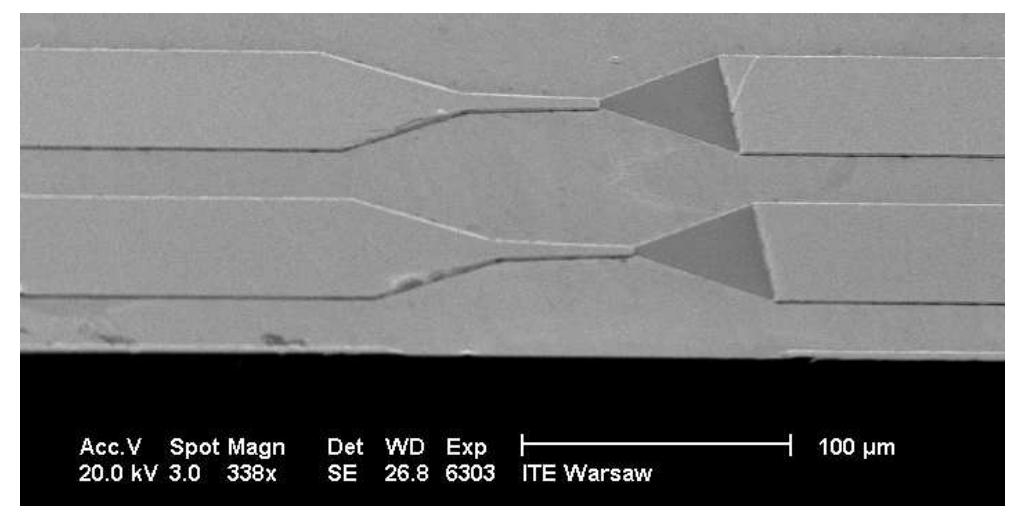

Fig. 2. SEM photograph of asymmetrically shaped device.

Finally, the structure was mounted into rectangular wave guide, and the microwave measurements were performed using a pulse modulated magnetron generator of $10 \mathrm{GHz}$ frequency. The pulse duration was $1.5 \mu \mathrm{m}$ and repetition rate was $35 \mathrm{~Hz}$.

\section{Results and discussion}

The sensitivity of the asymmetrically necked structures is proportional to the carrier mobility, as it follows from the phenomenological theory [6]. Thus, if the material with high mobility was used, the voltage sensitivity of the device should be higher.

The idea of the increase in electron mobility was implemented by employing the pseudomorphic modulation doped AlGaAs/InGaAs/GaAs structures containing a single $\mathrm{In}_{0.15} \mathrm{Ga}_{0.85} \mathrm{As}$ channel. Experimental power dependences of the detected voltage on microwave power of the asymmetrically shaped structures with the neck $d=7 \mu \mathrm{m}$ are presented in Fig. 3. The experiment shows that for 


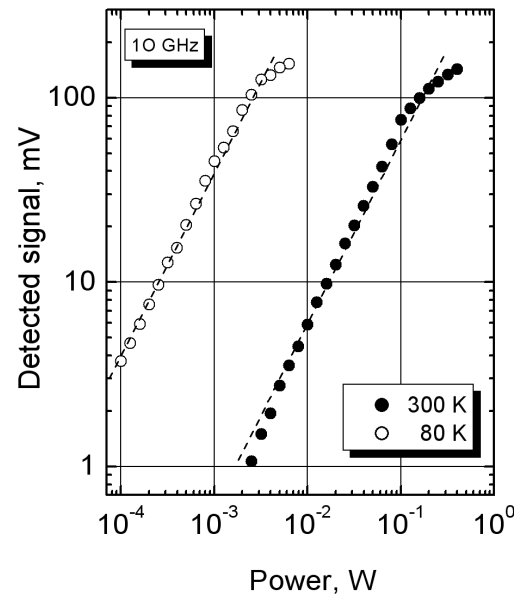

Fig. 3. Voltage power characteristic of asymmetrically shaped pseudomorphic structure. Dotted line shows a linear dependence as a guide for eye.

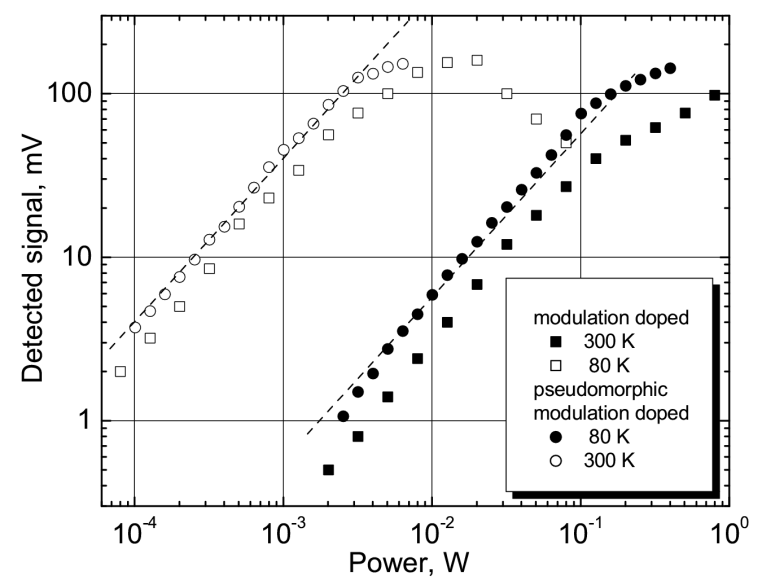

Fig. 4. Dependence of the detected signal on microwave power: AlGaAs/GaAs device versus the pseudomorphic AlGaAs/InGaAs/GaAs modulation doped device.

$10 \mathrm{GHz}$ the detected signal behaves linearly of low values of microwave power. The decrease in lattice temperature greatly increases the sensitivity of the device: at $300 \mathrm{~K}$ it is around $0.6 \mathrm{~V} / \mathrm{W}$ while, at liquid nitrogen temperature the value reaches $38 \mathrm{~V} / \mathrm{W}$, i.e. it increases by the factor of more than 60 . Comparing this number with the relative increase in the electron mobility with temperature one can infer that the latter effect is mainly responsible for the observed rise in the voltage sensitivity.

Power dependence of the detected signal of the pseudomorphic modulation doped AlGaAs/InGaAs/GaAs structure as well as AlGaAs/GaAs structure [3] are 
shown in Fig. 4. It is evident that the pseudomorphic structure is more attractive in the microwave range at $80 \mathrm{~K}$ temperature, where its sensitivity is about $38 \mathrm{~V} / \mathrm{W}$ compared to $20 \mathrm{~V} / \mathrm{W}$ of modulation doped AlGaAs/GaAs structures [3]. From the diagram it is seen that sensitivity of the pseudomorphic structures is twice higher than that of the modulation doped structure at room temperature.

\section{Conclusions}

We have investigated an asymmetrically shaped device based on pseudomorphic modulation doped AlGaAs/InGaAs/GaAs structure as a microwave device operating on the basis of non-uniform heating of the two-dimensional electron gas. The voltage sensitivity of the device at $300 \mathrm{~K}$ is $0.6 \mathrm{~V} / \mathrm{W}$ at $10 \mathrm{GHz}$, while at $80 \mathrm{~K}$ it has the value of $38 \mathrm{~V} / \mathrm{W}$. The voltage sensitivity of the AlGaAs/InGaAs/GaAs structure is 2 times higher than that of the modulation doped AlGaAs/GaAs structure.

\section{Acknowledgments}

This work was partially supported by Cephona Centre of Excellence (Poland), NATO Science for Peace Programme under the project No. 978030, and Lithuanian State Science and Studies Foundation under contract V-06071. A.K. thanks Cephona Centre of Excellence for the financial support.

\section{References}

[1] S. Ašmontas, A. Sužiedèlis, J. Thermoelectricity 1, 5 (1997).

[2] A. Sužiedèlis, J. Gradauskas, S. Ašmontas, G. Valušis, H.G. Roskos, J. Appl. Phys. 93, 3034 (2003).

[3] A. Juozapavičius, A. Ardaravičius, A. Sužiedèlis, A. Kozič, J. Gradauskas, J. Kundrotas, D. Seliuta, E. Širmulis, A. Ašmontas, G. Valušis, H.G. Roskos, K. Kohler, Semicond. Sci. Technol. 19, S436 (2004).

[4] K.T. Chan, M.J. Lightner, G.A. Patterson, K.M. Yu, Appl. Phys. Lett. 56, 2022 (1990).

[5] J. Misiewicz, G. Sȩk, P. Sitarek, Photoreflectance Spectroscopy of Semiconductor Structures, Publishing House of the Wrocław University of Technology, Wrocław 1999, p. 201 (in Polish).

[6] A. Sužiedèlis, S. Ašmontas, Int. J. Infrared Millim. Waves 15, 525 (1994). 